\title{
Experimental analysis of VCR Di diesel engine using Calophyllum inophyllum Bio Diesel
}

\author{
K.V.L.Bhuvaneswary* and Digvijay.B.Shelke \\ Department of Mechanical Engineering, SPPU, Dr.D.Y.Patil School of Engineering Academy,Talegaon, India
}

Accepted 15 June 2016, Available online 20 June 2016, Special Issue-5 (June 2016)

\begin{abstract}
Biodiesel in recent days are so extensively studied for the sake of using it as an alternate fuel in diesel engine which constitutes the major role in transportation. In the current paper the Calophyllum Inophyllum biodiesel is prepared by using thermal cracking process. The thermo properties of the biodiesel derived from the above process is tested according to ASTM standards. Experiments were conducted on Variable Compression ratio Engine and Performance parameters were determined like Brake Power, Brake Specific Fuel Consumption, Volumetric and Brake Thermal Efficiency. Later Exhaust Emission parameters like $\mathrm{CO}_{1} \mathrm{CO}_{2}, \mathrm{HC}$ and $\mathrm{NOx}$ were determined for biodiesel-diesel blends of 20\%, 40\%, 60\%, 80\% and 100\%, by incrementing load by 25\% and varying compression ratio from 15.5 to 17.5 at constant speed of 1500 rpm, injection pressure of 200 bar and injection timing of $27^{\circ} \mathrm{bTDC}$. The emissions shown by Pure Calophyllum biodiesel and B20 are much better and cleaner in comparison to diesel wherein the Carbon monoxide emission and Hydrocarbon emission reduced by 52\% and 49.8\%. The Nitrogen Oxides emission rose due to significant raise in exhaust gas temperature by $2.1 \%$. The Brake specific fuel consumption and Brake Mean Effective pressure increased by $24.3 \%$ and $52 \%$.
\end{abstract}

Keywords: Fatty Acid Methyl ester, Calophyllum Inophyllum Biodiesel, Variable compression ratio Diesel Engine, Emissions and Performance.

\section{Introduction}

Biodiesel stands for any diesel fuel replacement derivative from renewable biological reserve. More exclusively, biodiesel is distinct as oxygenated, sulfurfree, biodegradable, non-toxic and eco-friendly alternative diesel oil. Chemically, it can be defined as a fuel self-possessed of mono-alkyl esters or methyl esters of long chain fatty acids derived from renewable sources, for instance vegetable oil, animal fat and used cooking oil which is designated as B100 and also they meet the special requirements such as the ASTM and the European standards. The conversion of vegetable oils into biodiesel is best possible way to use in engine. There are many techniques to convert the vegetable oil into biodiesel and reduce its viscosity. There are many seeds of trees from which the oil can be extracted. The present work is done on Calophyllum Inophyllum from the Clusiaceae family. There are various names given in various languages like honne oil, puna oil etc. Many investigations were done on this oil by varying parameters like load, compression ratio, injection timing and pressure on both performance and emission with pure and blends with diesel. Collection of seeds and oil extraction and then proceeded for

*Corresponding author: K.V.L.Bhuvaneswary biodiesel production of Calophyllum Inophyllum Linn ("honne") Oil and understand its physical chemical properties. with molar ratio $8: 1, \mathrm{KOH}$ were $1.2 \mathrm{wt} \%$, temperature $65^{\circ} \mathrm{C}$, reaction time 90 minutes were used and testing of parameters as per ASTM 6751 standards. The thermo physical properties such as acid value density, Flash point, Calorific value, Fire point and Moisture, shows of calophyllum methyl esters were $0.702,892 \mathrm{gm} / \mathrm{cc}, 176^{\circ} \mathrm{c} 37.18 \mathrm{MJ} / \mathrm{Kg}, 182^{\circ} \mathrm{c}$ and $0.01 \%$ .The physico-chemical parameters proves that Calophyllum may be possible replacement as a reliable fuel as per ASTM. (Chavan S.B et al.,2013)

B.K Venkanna et al 2011 conducted test on CI engine for Honne oil and neat diesel to determine performance and emission characteristics at varied Injector opening. Experiments were carried out with different IOP of 200 to 260 bars. It was observered that the BTE increased when the IOP was varied from $200 \mathrm{bar}$ to 240bar because of good atomization and better mixing. The variation of EGT was observed highest at 200 bar for $\mathrm{H} 100$ but the thermal efficiency was found lowest. Emission characteristics like CO, HC for H100 dropped as the IOP increased and reached to least at 240 bars. Smoke opacity decreased with increase in IOP. NOx emission was higher with increased IOP. It was concluded that $\mathrm{CO}, \mathrm{HC}$, smoke opacity reduced as the IOP increased. NOx was 
increased as IOP increased. Also, the BTE was high and Ignition delay was reduced with increase in IOP .

S V Channapattanaa et al. 2015, conducted testing on the Calophyllum Inophyllum linn oil for determining emission and thermal performance on DI CI VCR engine. Tests were conducted on blends of biodiesel and standard diesel as a fuel at compression ratios of $15,16,17$ and 18 . They found that as the CR increases, BTE increases for increased Honne bio diesel blends But at highest CR, BTE reduced by $8.9 \%$ for Honne biodiesel compared to diesel. As CR increased, BSFC decreased for all biodiesel blends. At maximum CR BSFC is found to be least. Also increase in biodiesel content EGT decreased with increase in CR. Emission Characteristics: At high Compression ratio they observed that $\mathrm{CO}, \mathrm{HC}$, Smoke emissions reduced because of the better combustion of the fuel at increased $\mathrm{CR}$. The emission of $\mathrm{CO}_{2}$ initially decreased and then increased as the blend concentration of Methyl ester increased. NOx emission rose for all blends of biodiesel and decreased for Diesel. At higher $\mathrm{CR}$, NOx emission is high. As the CR value increases the performance observation of Methyl ester is found similar to that of Conventional diesel

C. Srinidhi et al 2014,. prepared Honne oil methyl ester and tests on the CI engine for Performance and emission with Honne Methyl ester and blends were compared with diesel. The performance conclusion was as the load increases BSFC decreases for the fuels and the blends. The BSFC of B 100 is increased 24\% to that of diesel fuel. The Brake thermal efficiency increases with the increase in load is what is observed. The BMEP of Diesel has increased by $53 \%$ on average with diesel. BTE B20 is similar to diesel but there is a $3 \%$ reduction in the performance $\mathrm{B} 100.11 \%$ reduction compared to diesel. EGT: 2\%increase for B20 and $5 \%$ increse for B100.NOx emission of B100 increased by $36 \%$. CO2 emissions for B100 is 14\% and B20 3\% respectively with respect to mineral diesel $\mathrm{HC}$ emission B20 exhibits a reduction by $14 \%$ and B 100 shows highest reduction of $\mathrm{HC}$ by $51 \%$. The results of the investigation showed that the Honne oil methyl ester diesel blends is comparable to the diesel in the aspect of performance.

Murugan K et al. 2015 conducted experiments on B20 and diesel by varying loads on a single cylinder four stroke diesel engine by the rope brake dynamometer. Exhaust emissions were measured with an AVL Di-Gas 444 exhaust gas analyzer. Honne oil has high viscosity and low calorific value than diesel so it has higher specific fuel consumption than diesel. The engine's Brake thermal efficiency increased and the emission of CO,HC and NOx were reduced by using B20 blend

Varathan R Karuppasamy K et al 2015 selected calophyllum inophyllum (Honne) oil and biodiesel was prepared by catalytic transesterification process Later Thermo Fluid properties was found for blends B25, B50, B75, B100. Experiments were conducted on Kirloskar single cylinder four stroke at CR value 16.5:1, Injection Pressure 240 bar, timing $23^{\circ}$ bTDC. As Brake power increased the Brake Thermal efficiency increased for all the blends of biodiesel and diesel. They observed maximum BTE of $38.86 \%$ for B25 against $45.16 \%$ of diesel. The specific fuel consumption was found high for the blends as the colorific value was less than diesel. The minimum BSFC (B100) is 0.065 $\mathrm{kg} / \mathrm{kWh}$ higher compared with diesel. The blends showed low $\mathrm{CO}, \mathrm{CO} 2$ and hydrocarbon emission when it is compared to the diesel. At higher loads it was observed that the HC emission decreased with increase of load. For biodiesel blends, the NOx emissions was high than the diesel which might be due to longer duration of higher temperature combustion. Performance, combustion and emission characteristics of $25 \%$ blend of Methyl ester and Diesel was found to be better than other blends and it showed a possible alternative for diesel as far as the results are considered.

Ashish G.Bandewar et al. 2015 conducted on test on CI engine at constant speed of 1500rpm, injection timing 27음ㄷㄴ and Injection pressures 210bar. The value of CR was varied from 14.5to 17.5 for BiodieselDiesel blends mainly, H25, H50, H75. At full load condition, when the compression ratio is varied from 14.5 to 17.5 , the biodiesel had highest CO emission at lower CR. At the highest CR value, CO emission is less for diesel when compared to Methyl ester. The NOx emission was found to be high for all blends at low CR value. HC emission decreased with increased CR because of complete combustion. It was concluded that the biodiesel blends had almost similar emission Characteristics with no modifications in the VCR engine. When antioxidants were added it increased BP and reduced BSFC slightly. Also in emission results it showed that CIB20 increased NOx but decreased HC and $\mathrm{CO}$ emission. The reduction percent of $\mathrm{NOx}$ emission was $1.6-3.6 \%$, but increased both $\mathrm{CO}$ and $\mathrm{HC}$ emission. It can be concluded that CIB20 blends with antioxidants can be directly used without any modification in diesel engines.

\section{2 .Preparation process of Biodiesel:}

Amongst the various method that are available for the preparation of Biodiesel, in this work the biodiesel is prepared by the process of thermal cracking of the crude oil. Thermal cracking is the chemical reaction in which the lower molecular weight products are produced from the organic compound. The crude oil usually has long chains hydrocarbon molecules and also higher viscosity. Cracking is one of the process in which the chains can be broken and the viscosity can be decreased.

For the purpose of preparation of biodiesel, a three necked flask packed with the column and then a condenser is used as a reactor for crude oil. An amount of $200 \mathrm{ml}$ oil is filled in the flask and $1 \mathrm{ml}$ of $\mathrm{HCl}$ is used as anti foaming agent. As crude oil has the capability to form foams which can be affected by possible impurities present in it. A heating metal is used for 
heating the crude oil for a maximum temperature of $250^{\circ} \mathrm{C}$. Porcelain bites were introduced into the flask in order to retain the uniform temperature inside the flask. Glass wool is used for the insulation purpose in order to reduce the heat loss to the surrounding(Deshpande DP et al, 2015) The condensed vapors were collected as the biodiesel was formed on the top and at the bottom glycerol was tapped. Later the biodiesel is separated and property tests were performed to understand if it can be used as the possible source for diesel engine. Further the biodiesel blends were prepared by volume fraction basis.

Table 1: Property Table of Biodiesel

\begin{tabular}{|c|c|}
\hline PROPERTY & B100 \\
\hline Density $(\mathbf{g m} / \mathbf{m l})$ & 0.768 \\
\hline${\text { Viscosity } \mathbf{~ m m}^{\mathbf{2}} / \mathbf{s e c}}^{\mathbf{}}$ & 4.3 \\
\hline Flash Point $^{\mathbf{C}}$ & 52 \\
\hline Fire Point $^{\mathbf{}} \mathbf{C}$ & 58 \\
\hline Net heating Value $\mathbf{M J} / \mathbf{k g}$ & 38690 \\
\hline
\end{tabular}

\section{Experimental Setup}

Experimentation was conducted on Diesel Engine test rig having single cylinder four stroke, D.I. water cooled type diesel engine with Eddy current loading for diverse fuel blends. The engine is a variable compression ratio engine.

\subsection{Experimental methodology}

The testing observations were recorded at constant Engine speed $1500 \mathrm{rpm}$, injection pressure of $200 \mathrm{bar}$ and injection timing of $27^{\circ} \mathrm{bTDC}$. Readings signify the engine parameters recorded were the variation in load and compression ratio with respect to all blends of Diesel-Biodiesel. The measurands are Thermal Performance and Exhaust emissions for different Blends of Bio diesel and the Diesel. The gas analyser used was 5-way in nature that can measure oxides of nitrogen, carbon (like $\mathrm{CO}$ and $\mathrm{CO}_{2}$ ) hydrocarbons in PPM or \% basis.

Table 2: Engine Specification and setup

\begin{tabular}{|c|c|}
\hline Make and Model & Rocket Engineering Model VRC -1 \\
\hline Type & $\begin{array}{c}\text { 4-stroke single cylinder, water } \\
\text { Cooled, Variable Compression Ratio } \\
\text { from } 14.5-17.5\end{array}$ \\
\hline $\begin{array}{c}\text { Standard } \\
\text { Dimensions of } \\
\text { Cylinder } \\
\end{array}$ & $\begin{array}{l}80 \mathrm{~mm} \text { bore diameter and } 110 \mathrm{~mm} \\
\text { length of stroke }\end{array}$ \\
\hline Speed & $\begin{array}{c}\text { 1500rpm Constant, governor } \\
\text { Controlled }\end{array}$ \\
\hline $\begin{array}{c}\text { Exhaust Gas } \\
\text { Analyser Make }\end{array}$ & Indus Scientific Pvt.Ltd. \\
\hline $\begin{array}{l}\text { Measureable } \\
\text { Gases }\end{array}$ & $\mathrm{CO}, \mathrm{CO} 2, \mathrm{NOx}$ and $\mathrm{HC}$ \\
\hline
\end{tabular}

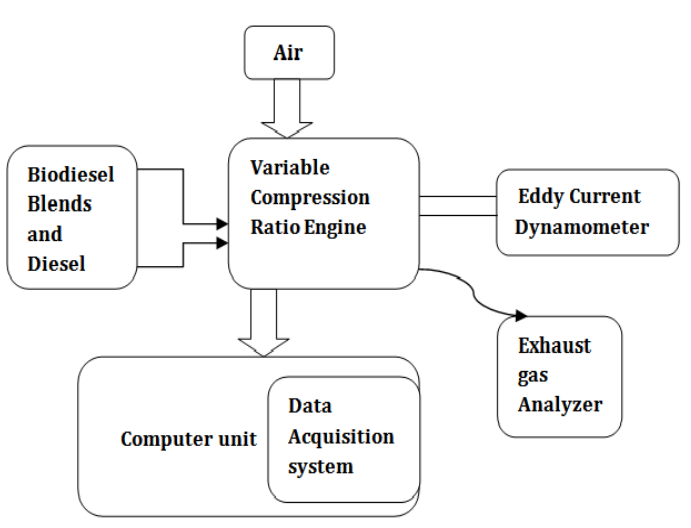

Fig1. Schematic representation of experimental setup

\section{Results and Discussion}

\subsection{Load Variation: Engine Performance}

The below experimental study reveals the variations observed when the load was altered for the blends.

\subsubsection{Brake Power}

Figure No 2. Illustrates the effect brake power derived from Callophyllum biodiesel to the load that is incremented by $25 \%$. Brake power of an engine is directly proportional to the load applied and hence the $\mathrm{BP}$ for all blends shows a linear variation. Also output power is found maximum for B20 Blend which contains $20 \%$ vol. Calophyllum methyl ester. The Brake power also derives the knowledge that the actual power delivered or obtained at the crankshaft reminding which is useful observation while considering a alternate fuel for current diesel engines without any high modifications.

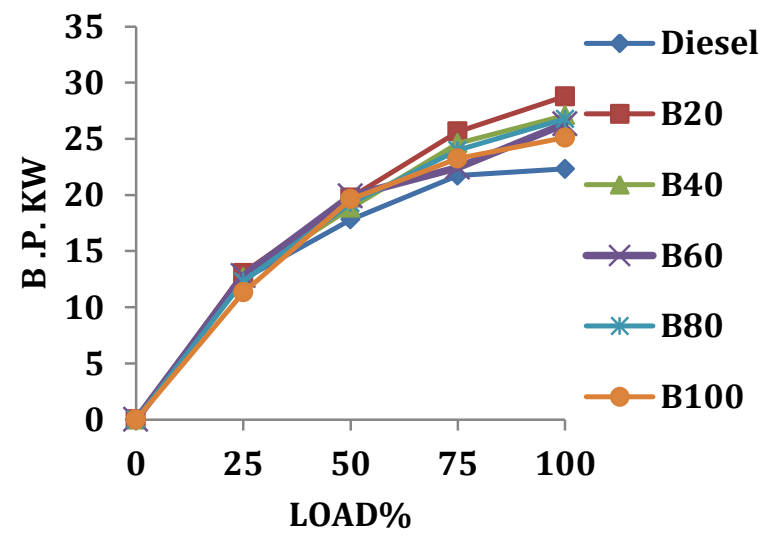

Fig2. Variation of Brake power to load

\subsubsection{Brake Mean Effective Pressure}

Brake mean effective pressure is a factor of turbulence occurring due to effective burning inside the cylinder recurring to greater BMEP .The figure 3 signifies that as the load increases the brake mean effective pressure 
rises almost linearly. Effective Pressure for diesel is very low in comparison to other mixtures. As the percentage of Calophyllum Methyl ester increases in the blend, relative increase in BMEP is found. Recordings were recorded at engine parameters of Compression ratio 17.5 and the Injection pressure 200bars. The Effective pressure of B100 (Calophyllum oil methyl ester) was maximum than all other the blends of biodiesel-diesel. The BMEP of Diesel has increased by $52.5 \%$ on average with conventional fuel.

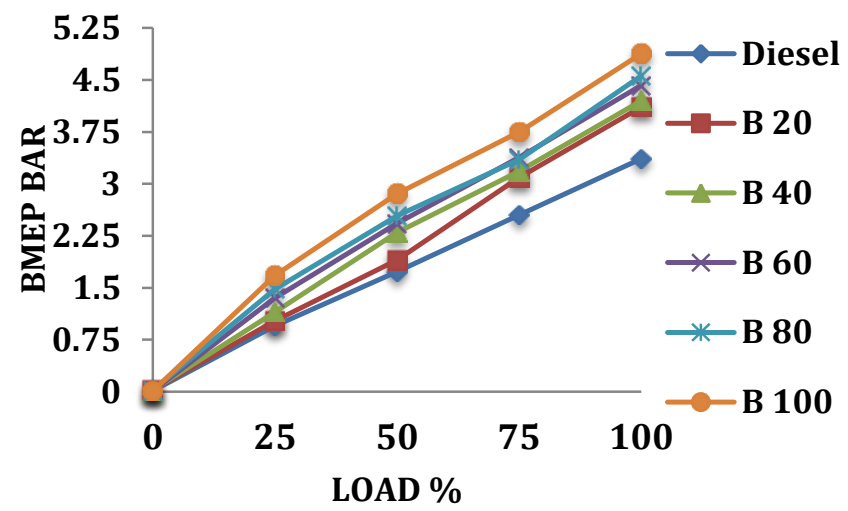

Fig.3. Variation of Brake mean Effective Pressure to load

\subsubsection{Exhaust Gas Temperature}

The exhaust gas expelled after the Power stroke contains some amount of heat or temperature which is allowed to the atmosphere. The figure 4 plotted below mentioned shows that as the load are altered on the output shaft the expelled gas temperature also increases. The amount of Heat released is directly proportional to exhaust gas temperature and also the heat release is important which is based on burning of fuel or which is also called as complete combustion. The trend observed for all the blends is the same but $\mathrm{B} 20$ is increased by $2.4 \%$. The compression ratio 17.5 , Injection pressure 200 bar and timing of $270 \mathrm{bTDC}$ were constant during observation. It is inferred from the graph that the B100 pure biodiesel is giving maximum exhaust gas temperature as the load is incremented.

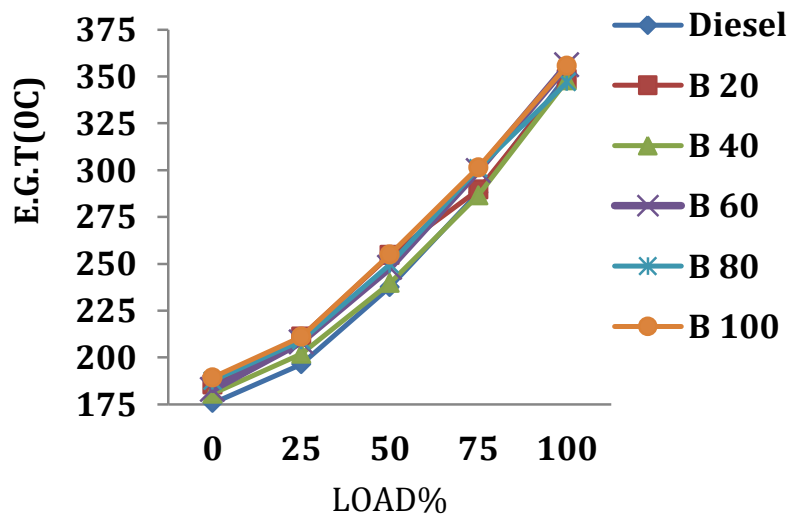

Fig.4. Variation of Exhaust Gas Temperature to load

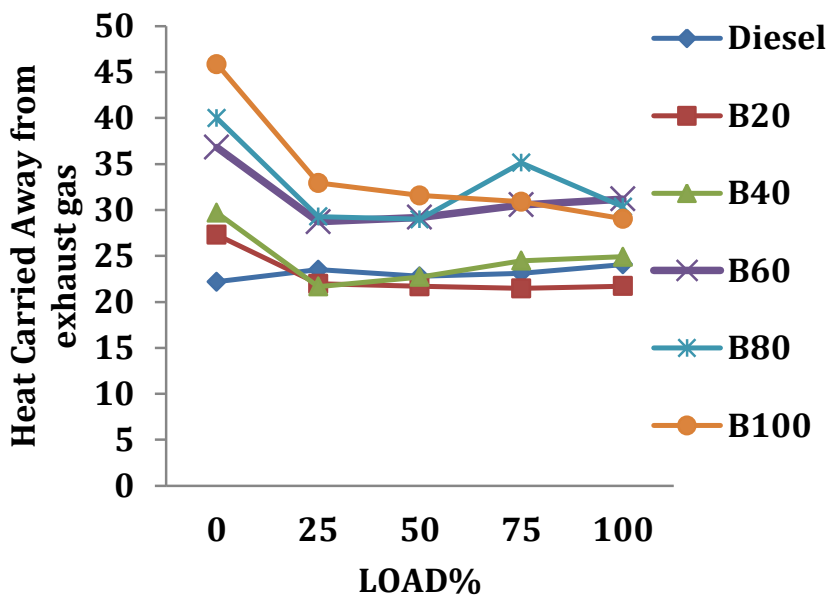

Fig.5. Variation of Heat carried away from exhaust gas to load

4.1.4. Brake Thermal Efficiency

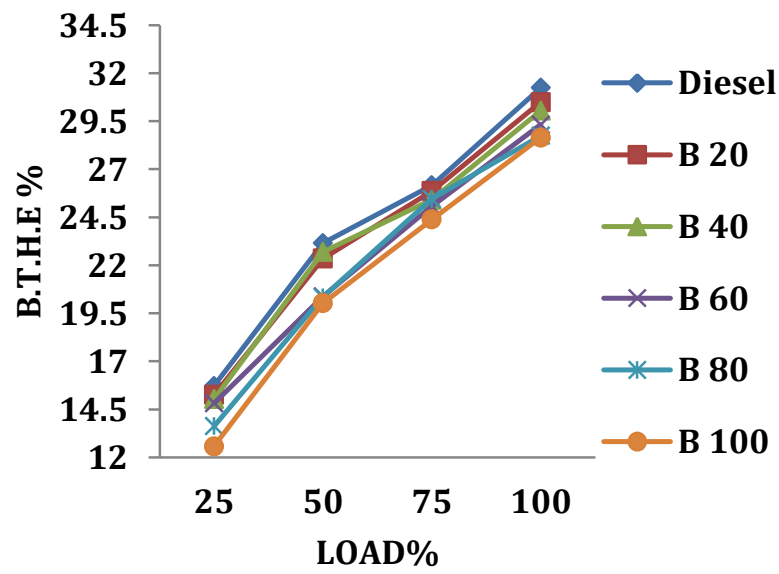

Fig .6. Variation of Brake Thermal efficiency to load

Brake thermal efficiency (\%) is the ratio of output power to heat supplied. The figure no 6 shows that the brake thermal efficiency for diesel is highest as the calorific value of diesel is higher than the other fuels. The brake thermal efficiency of all fuels used in the study is showing an increasing trend to load variation. The heat input provided is given by the mass of fuel consumed and the calorific value of the fuel. The bthe of B20 is almost same at lower loads but as the load increases, the average reduction is $3 \%$ with comparison to diesel. In the case of B100 the bthe reduces on a average load of $11 \%$. The brake thermal efficiency of B100 is lowest and fossil diesel is highest.

\subsubsection{Brake Specific fuel Consumption}

The BSFC shows the amount of fuel consumed for obtaining $1 \mathrm{~kW}$ of output power. The fig 7 describes the variation of the B.S.F.C with the load in all the biodiesels.The fact that conventional having higher heating value gives least BSFC which is good and as the blend percentage of Callophyllum biodiesel increases 
the BSFC Also increases which is disadvantage when such fuels are considered. The BSFC of B20 blends shows the same as diesel and for B100 the Specific fuel consumption is maximum. The bsfc for $100 \%$ biodiesel is $24.3 \%$ more than that of diesel fuel.

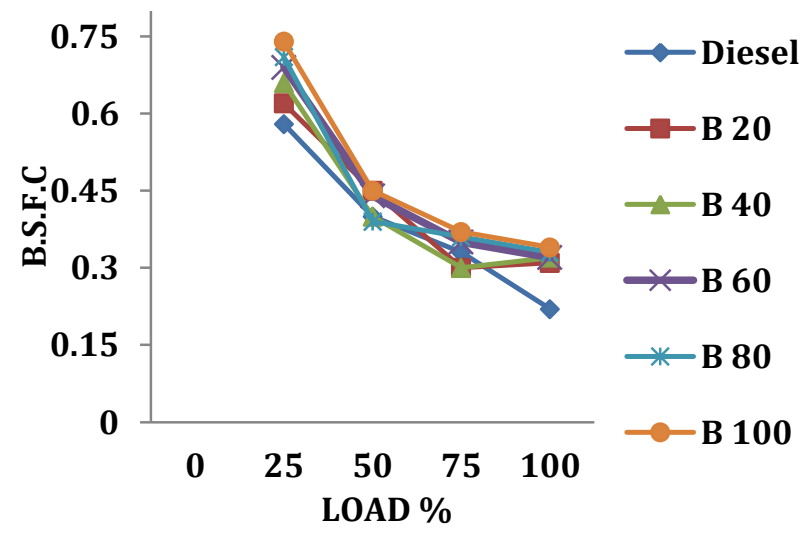

Fig.7. Variation of Brake Specific Fuel to Consumption to load

\subsubsection{Volumetric efficiency}

The figure 8 indicates the variation of the volumetric efficiency with the load for calophyllum-diesel blends. The volumetric efficiency is the ratio of actual air taken in to the theoretical air sucked inside the cylinder. The Vol efficiency is highest for B20 blend and lowest for conventional fuel or diesel. For B60 blend it first rises and gradually falls

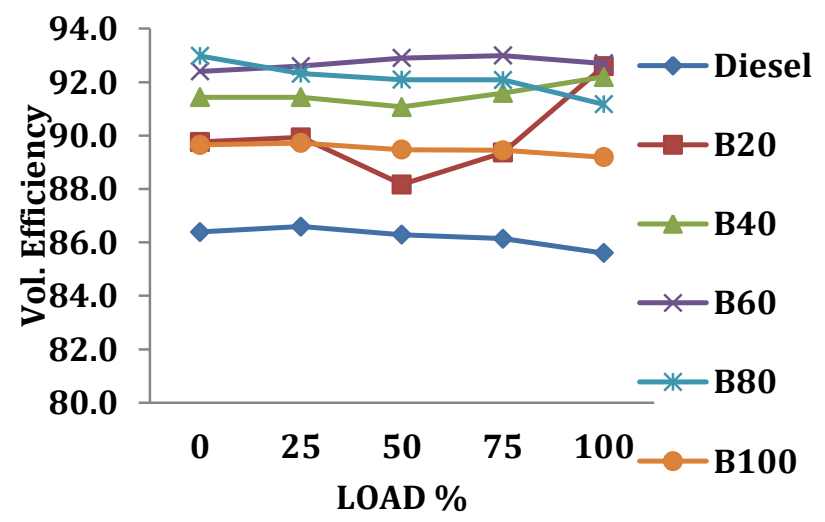

Fig.8. Variation of Volumetric efficiency to load

\subsection{Exhaust Emission}

\subsection{1 $\mathrm{CO}_{2}$ emission}

The fig 9 shows the emission of $\mathrm{CO}_{2}$ with the load incrementation for all the blends. Release of carbon dioxide emission is a sign of cleaner emission. As the amount of the biodiesel percentage increases the $\mathrm{CO}_{2}$ levels also increases which is good sign for alternate fuel. Even diesel doesn't show the the above statement. When load is increased the fuel consumption increases, the carbon dioxide emmision also shows the result in a linear progressive fashion. The $\mathrm{CO}_{2}$ emission for B100 is highest and least for diesel. The increase in carbon dioxide emissions for B100 and B20 is 13.5\% and $3.8 \%$ respectively to diesel.

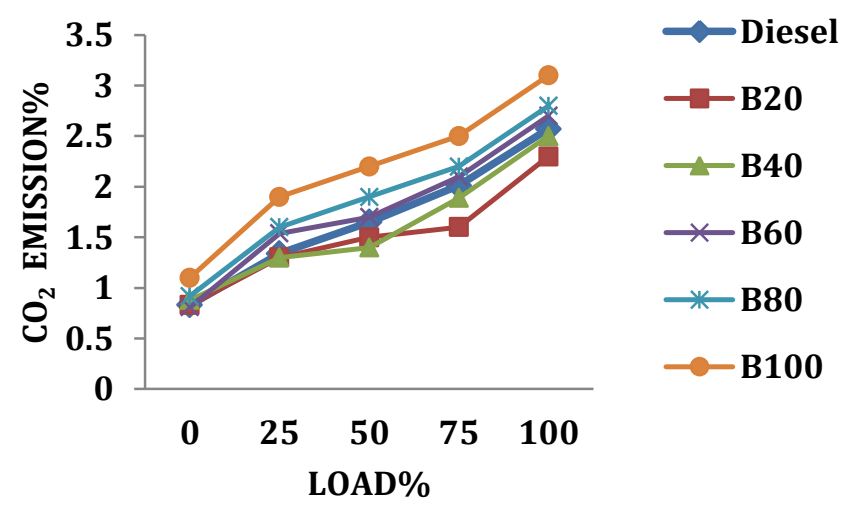

Fig. 9. Variation of $\mathrm{CO}_{2}$ to load

\subsubsection{Carbon-Monoxide Emission}

The figure 10 depicts the variation of $\mathrm{CO}$ with the increase in load. The load is incremented by $25 \%$ i.e. 0 , $3,6,9,12 \mathrm{~kg}$ 's. The CO forms when incomplete burning of fuel takes place. Also flame quenching es CO emission Also these emissions required the following reasons like oxygen content is lesser than theoretical or time shortage for combustion is lesser.

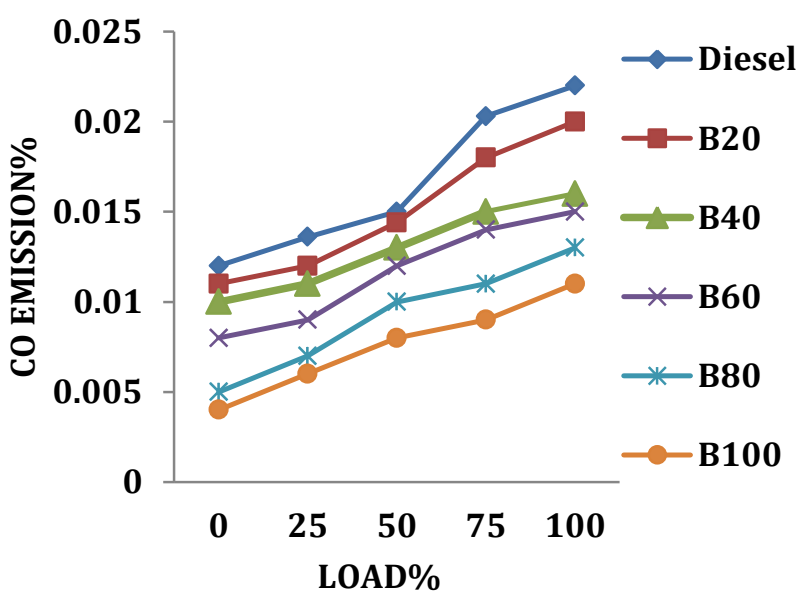

Fig .10 Variation of CO emission to Load.

At constant injection timing of $27^{\circ} \mathrm{bTDC}$, the $\mathrm{CO}$ emissions of Diesel fuel is highest and is measured in $\%$. The B100 blends show a reduction by 52\% than that of diesel and B20 by 12\% for all loads.

\subsubsection{Hydrocarbon emission}

The hydrocarbon emission (HC) is consequential of partial burning. As the load is varied, the HC emission grows. The figure 10 given below indicates the variation in the HC with load in as the blend. The hydrocarbon emission for conventional fuel diesel is 
found maximum. As the amount of biodiesel increases in the fuel hydrocarbon emission reduces significantly. B20 shows a reduction of HC emission by $13.5 \%$ and B 100 by $49.8 \%$.

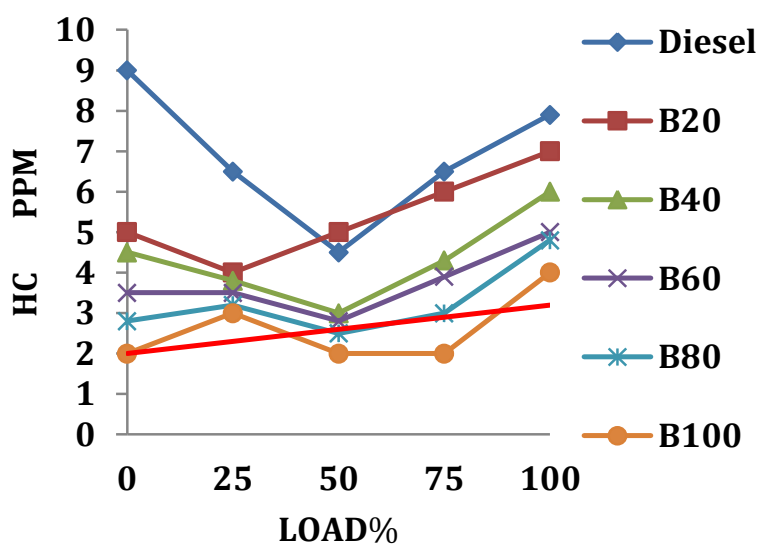

Fig . 11. Variation of Hydrocarbon emission to Load

\subsubsection{Nitrogen Oxides emission}

The variation of Nitrogen Oxides with respect to load is plotted graphically in figure 11 . The nitrogen oxides (NOx) emission is a direct function of burning temperature of the fuel in the combustion chamber inside the engine. The fluctuation of load and Oxides of nitrogen is showing a linear trend. The NOx produced by $\mathrm{B} 100$ is highest as combustion is found to be complete as due to the chemical structure of biodiesel has oxygen impregnated in it and which is absent in diesel. The NOx emission of B100 increased by 23\% in comparison to diesel

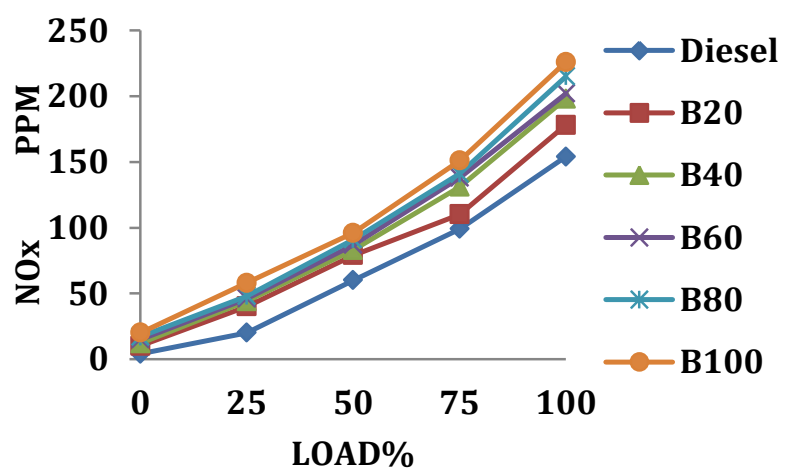

Fig .12 Variation of nitrogen oxide emission to Load

\subsection{Compression Ratio Variation: Engine Performance}

The below experimental study reveals the variations observed when the Compression ratio was altered for the same blends. The readings were noted at full load or maximum load.

\subsubsection{Brake Specific fuel Consumption}

It is observed that as the blend percentage increases the brake specific fuel increases which is illustrated in figure 13. This might be due to, Net heating value of diesel, which is higher than other biodiesel blends. B100 depicts maximum brake specific fuel consumption in comparison to all other blends. The brake specific fuel consumption of B20 blend increases as much as 3.8\% in comparison to Diesel fuel for all CR values. The bsfc values of diesel is much lesser in comparison to other blends.

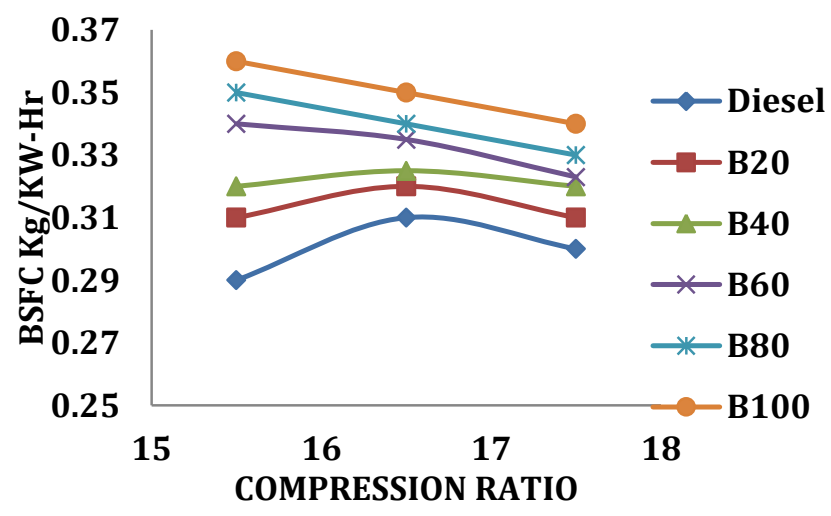

Fig. 13. Variation of BSFC to Compression Ratio

\subsection{Brake Thermal Efficiency}

The brake thermal efficiency is proportionate to the calorific value of fuel and is usually mentioned in $\mathrm{kJ} / \mathrm{kg}$. Also the rate of mass fuel consumed ( $\mathrm{kg} / \mathrm{hr}$ or $\mathrm{kg} / \mathrm{sec}$ ). The Brake thermal efficiency is adverse of Brake specific fuel consumption which is plotted for various compression ratios.

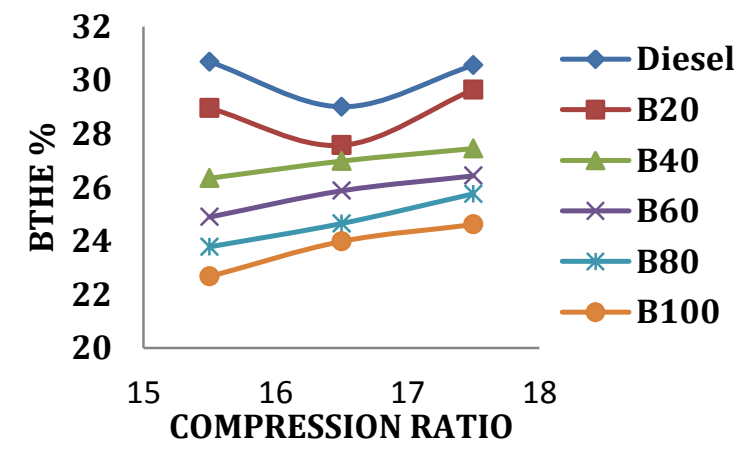

Fig. 14. Variation of BTHE to Compression Ratio

It is observed that the Brake thermal efficiency is highest for conventional diesel and lowest for B 100 . Also it is observed that, as the blend percentage increases the Brake thermal efficiency decreases. Even when the CR values are increased the BTHE also increases which is a significance of complete combustion. The appropriate standard compression ratio according to the manufacturer is varied from 17.5 -18 as depicted in figure 14.

\subsubsection{Break Mean Effective Pressure}

Brake mean effective pressure is the approximate turbulent pressure developed inside the engine cylinder required to move the piston. 


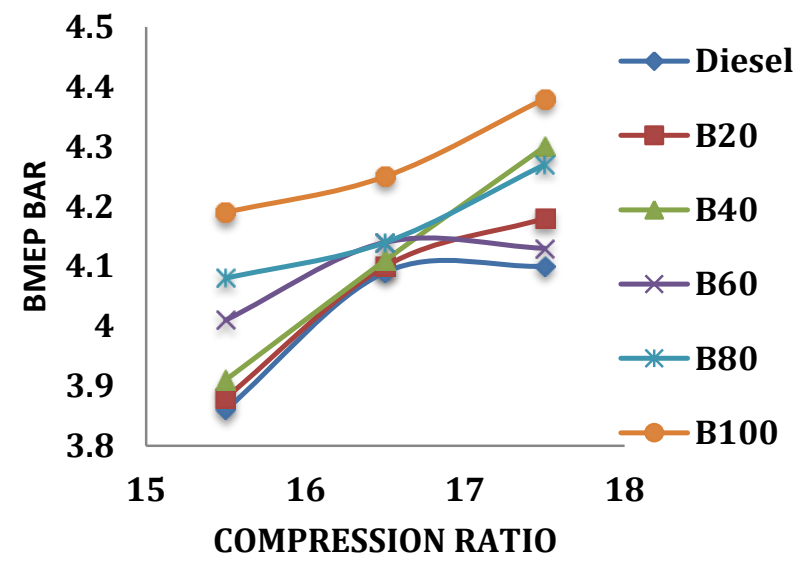

Fig. 15. Variation of BMEP to Compression Ratio

In the figure 15 the Effective pressure increases with $\mathrm{CR}$ rating, also the $\mathrm{BMEP}$ increase as the blend percentage increases. The Brake mean effective pressure of pure Callophyllum oil is highest as 4.2 bar at compression ratio of 16.5 and 4.45 at $\mathrm{CR}$ value 17.5 .

\subsubsection{Volumetric Efficiency}

The Volumetric efficiency of Diesel found is remarkably less than all other fuel blends of bio diesel. The figure 16 shows in the observations that, the percentage of Bio Methyl ester increases the volumetric efficiency at first and later decreases.

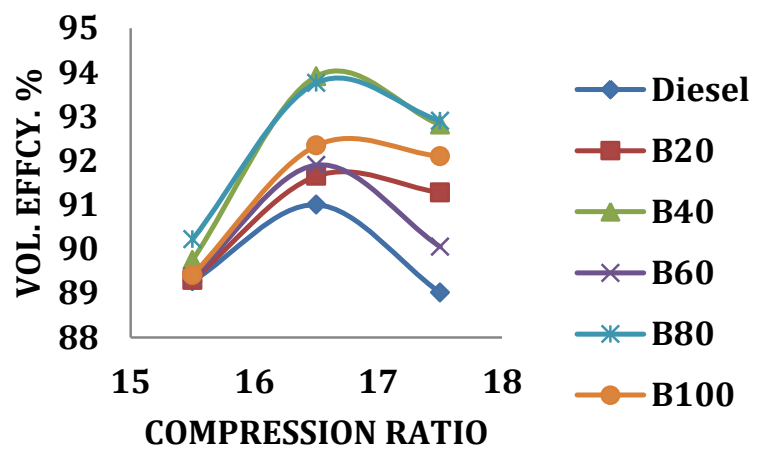

Fig.16.Variationof Vol. Efficiency to Compression Ratio

Also as the percentage of the blend increases, the graph remarks similar characteristics to that of conventional diesel. As the compression ratio increases the volumetric efficiency increases in all the blend and also in the diesel and later decreases. The volumetric efficiency in more for B20 than diesel.

\subsection{Exhaust Emission}

\subsubsection{Carbon dioxide Emission}

The figure 17. Shows the graphical representation of Carbon dioxide emission of all the blend and diesel with the increase in compression ratio is shows that carbon dioxide emissions of diesel fuel found is very less and as the blend percentage of biodiesel increases the carbon dioxide emission also increases which is adverse fact for $\mathrm{CO}_{2}$ emission. As the compression ratio is increased from 15.5-17.5 in units of $1 \mathrm{CR}$ value. The $\mathrm{CO}_{2}$ emission decreases slightly. The blending plays an important factor showing that, as the blend percentage increases the $\mathrm{CO}_{2}$ increases. Diesel shows the lowest readings of $\mathrm{CO}_{2}$.

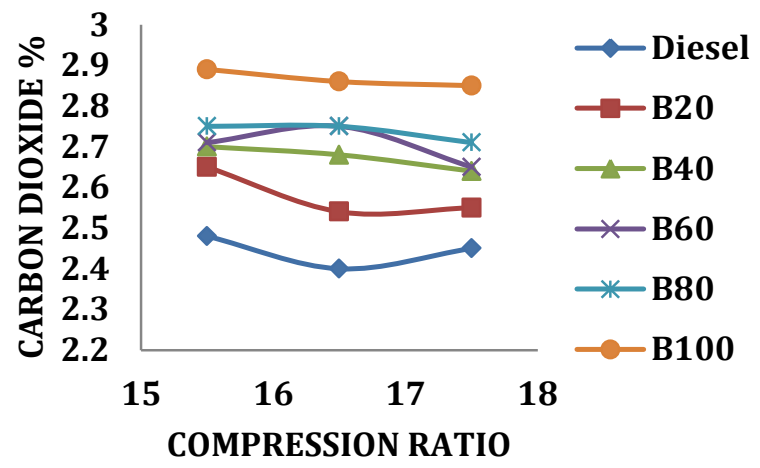

Fig.17.Variation of $\mathrm{CO}_{2}$ to Compression Ratio

4.4.2 Carbon monoxide Emission

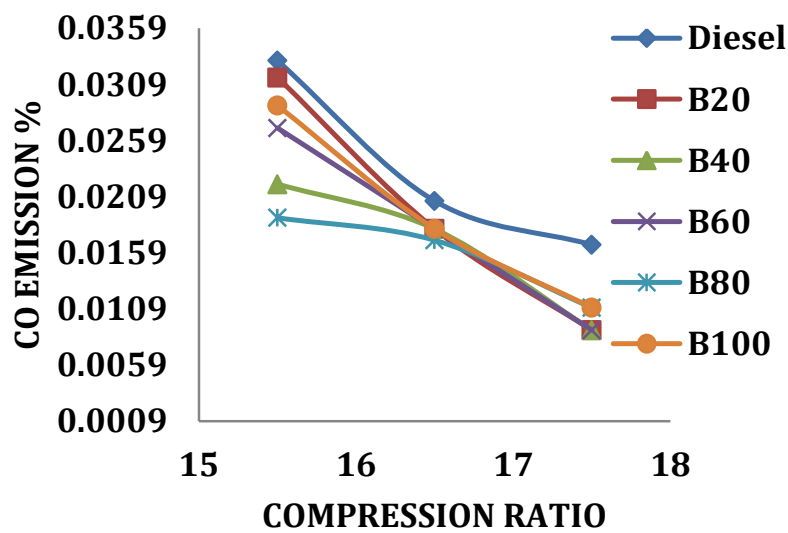

Fig.18.Variationof CO to Compression Ratio

The Figure 18. shows the variation of $\mathrm{CO}$ with Compression ratio with all the biodiesel blends. The carbon monoxide emission is a derivative of incomplete combustion, either by insufficient oxygen or time lack to undergo complete combustion. At various compression ratios, the $\mathrm{CO}$ emission of diesel fuel is in high. But as the percentage of Bio diesel increases in the Blend, the emission of carbon monoxide decreases. It is found that the lowest $\mathrm{CO}$ emission is found for B 100. It might be that oxygen molecule present in the fuel which adds up for combustion thereby increasing the combustion efficiency and effective burning of methyl ester as fuel.

\subsubsection{Hydrocarbon Emission}

It is observed from the figure 19 that Hydrocarbon emission is inversely proportional to compression ratio. The optimized compression for $\mathrm{CI}$ engine when 
diesel is used is 17.5 and to this range we may have lesser amount of Hydrocarbon emission. Higher the compression ratio results in cleaner combustion. The hydrocarbon emission is higher in diesel than compared any bio diesel blends .It is seen that B100 has the least $\mathrm{HC}$ emission as the compression ratio increased.

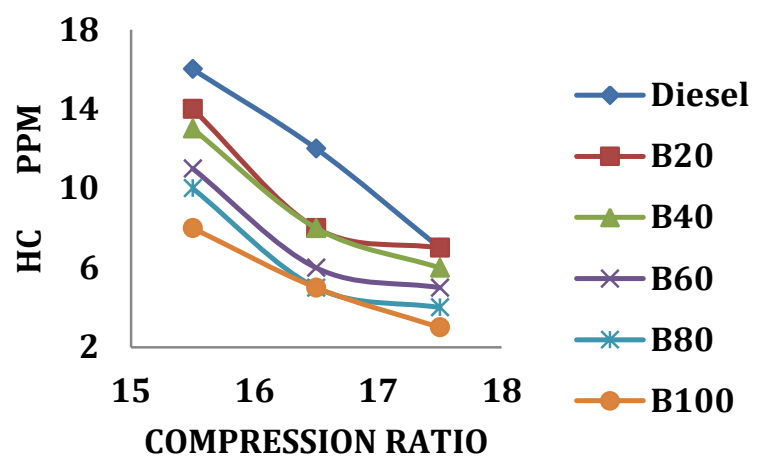

Fig.19. Variationof Hydrocarbon to Compression Ratio.

\subsubsection{Nitrogen Oxide Emission}

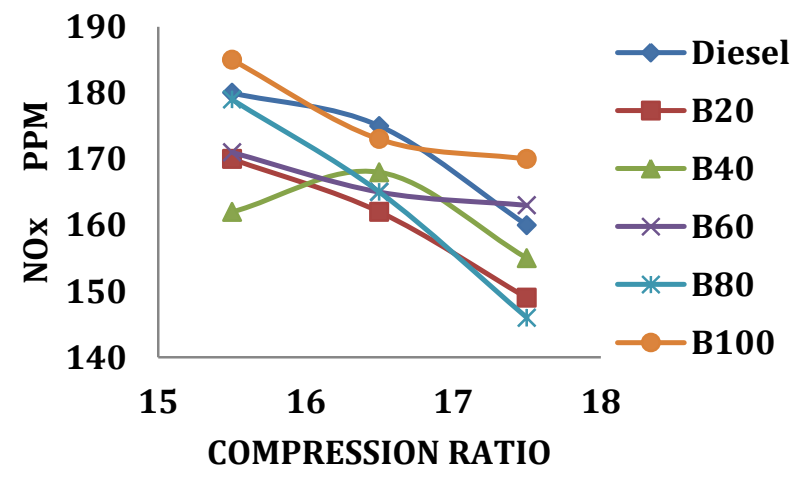

Fig.20.Variationof NOx to Compression Ratio

Formation of Nitrous Oxides is a function of temperature. It is found that the NOx emission is highest for the B100, which might be due to higher Oxygen presence in structure in chemical structure resulting in higher exhaust gas temperature. When the compression ratio increases the emission of $\mathrm{NOx}$ decreases for all the blends and also diesel. The $\mathrm{NOx}$ emission for B80 and B20 blend is the very less when compared to the other blend

\section{Conclusion}

The experimental analysis of biodiesel derived from from calophyllum oil is compared to diesel with the variation of engine load incrementing by $25 \%$ and then with the variation of compression ratio observes the following points.

- The Brake thermal efficiency reduced by 3\% and $12 \%$ for B20 and B100 in comparison of diesel with the variation of load and the brake specific fuel consumption increased by $24.3 \%$ for B100 with that of diesel which is a negative point when mileage concept is considered.
- The Brake Mean Effective pressure raised by $52 \%$ for B100 which adds to point of higher combustion efficiency.

- The Hydrocarbon and Carbon monoxide emissions reduced by $49.8 \%$ and $52 \%$ which proves a cleaner fuel but the NOx increased by $23 \%$ for B100 with reference to the load variation.

- While varying compression ratio, the brake thermal efficiency of B20 and B100 reduced by $4 \%$ and $21 \%$ with comparison to diesel and the Brake specific fuel consumption increased by $14 \%$ for B100 as to diesel when the compression ratio is increased.

- The Hydrocarbon emission and the carbon monoxide emission reduced $54 \%$ and $17.26 \%$ for $\mathrm{B} 100$ and $17.1 \%$ and $16.5 \%$ for B20 with comparison to diesel as compression ratio increased.

\section{References}

Chavan S.B., Kumbhar R.R. and Deshmukh R.B (2013), Callophyllum Inophyllum Linn ("honne") Oil, A source for iodiesel Production, Research Journal of Chemical Science Vol. 3(11),pp 24-31.

B.K Venkanna C.Venkataramana Reddy.2011, Influence of injector pressures on performance, emission and combustion characeterices of DI diesel engine running on Calophyllum Inophyllum linne oil International Journal of Renwal energy. Vol6. No1, pp 15-17

S V Channapattanaa*,Kantharaj Cb,V S Shindec Abhay A Paward, Prashant G Kamble,2015, Emissions and Performance Evaluation of DI CI - VCR Engine Fuelled with Honne oil Methyl Ester / Diesel Blends Science Direct Energy Procedia 74,pp $281-288$

C. Srinidhi ,S.V.Channapattana J.A. Hole, A.A.Pawar P.G.Kamble ,2014,Investigation On Performance and Emission Characteristics Of C.I. Engine Fuelled With Honne Oil Methyl Ester : International Journal of Engineering Science Invention ISSN (Online): 2319 - 6734,Volume 3 Issue 5 pp.59-66

Murugan K, Udhayakumar K Performance and Emission Characteristics of Biodiesel using with Tamanu Oil in Single Cylinder Four Stroke Diesel Engine: IOSR Journal of Mechanical and Civil Engineering (IOSR-JMCE) e-ISSN 2278-1684, p-ISSN: 2320-334X pp 55-60

Varathan R Karuppasamy K,2015, Performance Emission and Combustion Characteristics of Honne Oil Biodiesel blends in Diesel Engine, International Journal of Mechanical Engineering and Research, ISSN 0973-4562 Vol. 5 No.1 pp38-41.

Ashish G.Bandewar, Raahul Krishna, SV Chanapattana, 2015,Experimental Investigation of Emission Characteristics of VCR engine using Calophyllum Inophyllum Bio-Diesel Blends as a Fuel International Journal on Recent Technologies in Mechanical and Electrical Engineering (IJRMEE) ISSN: 2349-7947

pp 22-25.

Deshpande DP, Dehankar PB, Adwant AV and Hakke VS 2015,Conversion of used Palm oil using CaCO3 as a Catalyst, International Science Congress Association, Vol. 5(3),pp 27-29 